\title{
The Role of Patriotism in Explaining the TV Audience of National Team Games- Evidence From Four International Tournaments
}

\author{
Stephan Nüesch and Egon Franck \\ Institute for Strategy and Business Economics University of Zürich
}

\begin{abstract}
In the literature addressing the determinants of TV audiences in sports, both the absolute and relative playing strength of the opponents play a prominent role. Regarding national team competitions, however, this study conjectures that patriotism matters as well. Analyzing the Swiss TV audience at 2 World Cups and 2 European Football Championships, this study finds strong evidence that TV ratings are highly affected by the sizes of the groups of foreign residents affiliated with the teams playing on the field.
\end{abstract}

Two of the world's most popular national team tournaments are the Fédération Internationale de Football Association (FIFA) World Cup and the Union of European Football Associations (UEFA) European Football Championship. The media coverage of these contests is remarkable: During the 2006 World Cup event, for example, 73,072 hr of dedicated programming were broadcast to 214 different countries and 26.29 billion estimated TV viewers (FIFA, 2007). Given that no league games are able to sustain comparable TV ratings, these big soccer events seem to appeal to those beyond the circle of regular soccer fans. A newly attained love for the game of soccer seems implausible as an explanation for this phenomenon. A more likely explanation lies in feelings of patriotism and national pride, which may be mobilized on a large scale during these events (Markovits \& Hellerman, 2001).

Despite the intuitive importance of patriotism in this context, empirical studies of TV audiences in sports (e.g., Alavy, Gaskell, Leach, \& Szymanski, 2006; Forrest, Simmons, $\&$ Buraimo, 2005; Kuypers, 1996) have not dealt with the phenomenon so far due to the focus on club competitions within leagues. This article aims to fill this gap by investigating the determinants of TV demand and the special role of patriotism in the case of televised national team games. Based on both an economic and a socio-psychological explanation of

Correspondence should be addressed to Stephan Nüesch, Institute for Strategy and Business Economics, University of Zürich, Plattenstrasse 14, CH-8032 Zürich. E-mail: stephan.nuesch@isu.uzh.ch 
why patriotism may be a strong driving force for consumption activities at national team competitions, we conjecture that the preference of a potential spectator to watch a specific game of the FIFA World Cup or the UEFA European Football Championship is (to a large extent) shaped by his or her citizenship. In a first attempt, we discovered a weakly significant, positive relation between the Swiss TV ratings of games at the FIFA World Cup 2006 and the numbers of the corresponding foreign residents living in Switzerland (Franck \& Nüesch, 2008). To draw conclusions based on only one tournament is precarious, however. This article amplifies the empirical basis as it incorporates data of four major soccer tournaments: the European Football Championships in 2000 and 2004 and the World Cups in 2002 and 2006. In line with the existing literature on consumer demand in sports (e.g., see Borland \& MacDonald, 2003, for an excellent review), we assume that the absolute playing strength of the opponents and the relative evenness of the competition (competitive balance) have a positive impact on TV audience figures as well.

Our hypotheses about the determinants of the demand for televised national games are tested using Swiss TV ratings. Among other advantages of this data set, which is discussed in more detail, the country covered by the data, Switzerland, offers a good quasi-experimental design to test the influence of patriotism. At over $20 \%$, Switzerland has one of the highest foreign resident rates worldwide, and these foreigners come from over 200 different countries. Our results show that both the expected absolute playing strength of the opponents and patriotism strongly predict the TV figures, whereas outcome uncertainty is irrelevant.

\section{TV AUDIENCE OF NATIONAL TEAM GAMES}

Whereas gate attendance is restricted by stadium capacity, TV demand is practically unrestricted due to the scale effects of the underlying technology. "Desired" and effective attendance is, therefore, identical in the case of a TV audience. For obvious reasons, factors like admission prices, travel costs, or income effects that matter in the case of stadium demand are less relevant for the decision to consume televised games. In sum, these conditions make it easier to reliably measure consumer behavior in the case of TV demand (Forrest et al., 2005). ${ }^{1}$

Considering the time and budget constraints the consumers face, it is obvious that the higher the utility of watching a particular national team game on TV, the more viewers will tune in, holding everything else constant. ${ }^{2}$ Borland and MacDonald (2003) described two main sources from which the fans may derive utility: the quality of the contest and their identification with a team in the contest. The quality aspect refers to both the absolute playing strength and the competitive balance of the competing teams. The most likely form of identification in the context of national team games is the affiliation of consumers with the team representing their nation at the tournament. This identification is reflected by the degree of patriotism. In

\footnotetext{
${ }^{1}$ Hammervold and Solberg (2006) directly asked TV viewers if they were willing to pay to watch different sports programs. Their results revealed that Norwegian soccer fans were significantly more motivated to pay than fans of other sports.

${ }^{2} \mathrm{An}$ anonymous referee correctly noted that income differentials between immigrants and nationals help to explain differences in TV consumption, as they largely determine the opportunity costs of time.
} 
the following two sections, we explain the concepts of (absolute) game quality, competitive balance, and patriotism as determinants of TV ratings.

\section{Game Quality}

Rottenberg (2000) defined the quality of a game as follows: "The quality of the game is higher, the more grace and skill with which it is produced, the larger the number of instances of extraordinary physical achievement that appears in it, and the more uncertain its outcome"3 (p. 11). High-quality soccer games involve much brilliance, spectacle, fighting, emotions, and a lot of fast ball movements and goal chances. Other factors, like aesthetics and elegance, may be very important, for example, in gymnastics or figure skating, but are less so in soccer. Madrigal (1995) argued that "sporting events represent a hedonic experience in which the event itself elicits a sense of drama" (p. 206). It is common to use the term "playing strength" to describe the ability of a team to produce "instances of extraordinary physical achievement," as well as the other aspects of quality described earlier.

\section{Competitive Balance}

Because a game is a product of at least two teams, not only the absolute playing strengths of the teams but also the inter-team comparisons are likely to affect fan interest. The uncertaintyof-outcome hypothesis (Neale, 1964; Rottenberg, 1956) postulates that fan interest increases for evenly matched and, therefore, unpredictable contests. Despite the fact that the empirical evidence of the benefits of competitive balance is far from unambiguous (see the reviews of Borland \& MacDonald, 2003; Szymanski, 2003b), the uncertainty-of-outcome hypothesis still enjoys high prominence in sports economics.

\section{Patriotism}

The phenomenon that fans tend to form attachments to particular teams, which they often support almost regardless of the quality of the game, is well known from league soccer and other team sports (Szymanski, 2003a). However, compared to club games in league soccer, national team games provide an additional source of consumer identification: the attachment to one's own nation represented by the team. Patriotism concerns "an affective attachment towards the in-group implying feelings of belongingness, responsibility and pride" (Mummendey, Klink, \& Brown, 2001, p. 160). Because soccer is the world's most widely played team sport, the chances to form patriotic attachments are greater than in any other sport. The choreography of the national team games additionally intensifies patriotic feelings by playing the national anthem before each game (Bogdanov, 2005). A Korean anthropologist considered the high national enthusiasm during the World Cup 2002 in South Korea as "at heart, a strong 'nationalistic' phenomenon" (Cho Han, 2004, p. 21).

\footnotetext{
${ }^{3}$ Although Rottenberg (2000) considered competitive balance as an element of game quality (similar to Borland \& MacDonald, 2003), we treat outcome uncertainty as a separate concept to prevent misunderstandings.
} 
Economic explanation of patriotic consumer behavior. The economic explanation of patriotic consumer behavior is based on two general premises: First, individuals behave rationally to maximize their utility (rational choice framework). Second, watching soccer is habit forming, which means that an individual's current preference depends on his or her past consumption activities. Most economists agree that past consumption activities often are an important determinant of present consumption patterns (e.g., see Pollak, 1970; Spinnewyn, 1981; Stigler \& Becker, 1977). Stigler and Becker used music as an example of how past consumption activities lead to beneficial addiction through an accumulation of the so-called "consumption capital." Having exposed themselves to music in the past, consumers have gained inside knowledge that enables them to derive more pleasure from listening to the same music in the present. Stigler and Becker themselves referred to Marshall (1923), who wrote: “... the more good music a man hears, the stronger is his taste for it likely to become"4 (p. 94). Applied to soccer, this means that the marginal benefit of watching a soccer game increases with the knowledge about the teams on the field. Therefore, given a certain budget constraint, consumers will not diversify indefinitely either across activities or across individuals or teams within a given activity, but will specialize in their consumption patterns. Apparently, consumption capital helps to explain persistent fan loyalty; however, it does not help to answer the question of who will concentrate on which team.

Adler (1985) provided an extension of the original Stigler and Becker (1977) framework by adding the element of accumulating consumption capital through discussion. Thus, teamspecific consumption capital may not only be increased through past consumption activities, but also through discussion of the team's performance with other fans who know about it. However, such communication is costly. It involves searching costs to find other competent discussants, as well as language transaction costs. In his article, Adler only considered the first aspect. Hence, he argued that fans tend to patronize the most famous team because the searching costs to find like-minded fans will be minimal as a consequence. The concept of language transaction costs introduced by Lang (1986) and expanded by Lazear (1999) adds an important insight to this analysis. Different languages and cultures can be viewed as a barrier in the accumulation of consumption capital through social interactions. Overcoming that barrier involves transaction costs in the form of opportunity costs of lingering misunderstandings, time or money spent on learning a language, using translators and other intermediaries, or, generally, on assimilating to a culture. A common culture (wherein language is one aspect) facilitates social interactions and lowers the language transaction costs. Thus, market forces encourage segregation and prevent the rise of one dominant team that everybody supports. Instead, the language transaction costs are minimized if team attachments are formed based on ethnic affiliations that involve the same language and culture. ${ }^{5}$ Nationals typically minimize both the searching and the language transaction costs by supporting the national team of the country in which they live. For immigrants, however, the optimal decision is likely to be different. Because consumption capital is irreversible and not transferable, it creates lock-in effects and significant switching costs. Language transaction costs additionally foster fan segregation along

\footnotetext{
${ }^{4}$ Original statement in Marshall (1923, p. 94) quoted in Stigler and Becker (1977, p. 78).

${ }^{5}$ In this article, we implicitly suppose that the ethnic affiliation is mainly driven by the political citizenship of a person. This assumption, however, is not always adequate. The United Kingdom is an interesting example of a state in which different ethnic nationalities (English, Scottish, Welsh, etc.) have evolved into a single state identity (British). Due to historical path dependencies, the United Kingdom is even allowed to have more than one "national" team in soccer.
} 
ethnic boundaries. Hence, we conclude that foreign immigrants tend to support the national team of their native country because, in doing so, they economize language transaction costs. As a consequence, they are able to derive the maximum net pleasure from watching and discussing the games. ${ }^{6}$

Socio-psychological explanation of patriotic consumer behavior. From a sociopsychological perspective, patriotic consumer behavior may be explained by people's tendency to classify themselves into social categories to facilitate self-definition and bolster self-esteem (Tajfel \& Turner, 1985). One of the group memberships that contribute to the (social) identity of a person is national affiliation. Benedict Anderson (1983) introduced the notion of "imagined communities" to explain the strong sociological bond to one's native country. Despite the fact that even members of small nations are never able to cultivate face-to-face contacts with all fellow members, Anderson noted that national belonging can activate "deep attachments" (p. 14). During international sports competitions, an otherwise "imagined" community becomes manifest by the appearance of the national team. Group lines are typically drawn very sharply, which increases the awareness of both the ingroup (in our case, the national team representing the own country) and the outgroup (the opposition national team). In such situations, individuals are likely to display strong identification with their ingroup (Ashforth \& Mael, 1989).

\section{ECONOMETRIC FRAMEWORK}

To analyze the determinants of a TV audience, we use the Swiss TV ratings of all matches of the FIFA World Cups 2002 in South Korea and Japan (World Cup 2002) and 2006 in Germany (World Cup 2006) and of the UEFA European Championships 2000 in Belgium and the Netherlands (European Championship 2000) and 2004 in Portugal (European Championship 2004). The TV figures consider all Swiss TV viewers who watched the national team games on 1 of the 17 different free TV channels on Swiss cable television, which serves over $90 \%$ of all Swiss households. ${ }^{7}$ Thus, potential selection bias due to missing satellite TV ratings is small. The ratings statistics were calculated by Publica Data using survey data of 1,870 Swiss households, equaling 4,160 people. The survey sample households have TV boxes in their homes that automatically record their TV viewing habits in 30-sec intervals. ${ }^{8}$

Our decision to analyze only the Swiss TV audience figures is motivated by the following: First, accurate worldwide TV figures are not available. Second, by examining just one country, we are not concerned with potential biases due to variations in TV contracts, for example, concerning different quotas of pay TV versus free TV games, which might influence the TV ratings. Third, as a country with a long history of accepting non-nationals, Switzerland offers a

\footnotetext{
${ }^{6}$ See also Franck and Nüesch (2008) regarding this argumentation.

${ }^{7}$ The TV ratings include viewers of the following channels: SF 1, SF 2, TSR 1, TSR 2, TSI 1, TSI 2, RTL, M6, ARD, ZDF, ORF 1, TF 1, F2, F3, RAI 1, RAI 2, and SAT 1. Thus, besides six Swiss channels (in 3 different languages) there are also four German, four French, two Italian, and one Austrian channel. The considered TV channels covered an estimated market share of $65 \%$ during the soccer competitions.

${ }^{8}$ The quota attributes used in the systematic drawings are language area, canton, district, size of household, household with or without children, and the age of the person who makes most of the purchases. Unfortunately, Publica Data does not collect any information about the citizenship of the households.
} 
good quasi-experimental design to test the influence of patriotism. Switzerland has one of the highest foreign resident rates worldwide at over $20 \%$, and the foreigners come from over 200 different countries. Fourth, being a multilingual country, Switzerland can be sub-sampled in three different language groups (French-, Italian-, and German-speaking regions) with varying foreign compositions. This allows us to test the robustness of our results.

\section{Explanatory Variables}

We have three main categories of explanatory variables: absolute and relative game quality indicators and a measure of patriotism. In soccer, quality measures are typically hard to find. The quality of the game is not only determined by the players' talent, but also by the cooperation and interaction within the team. We need, therefore, a measure that reflects the absolute playing strength of the national team as a whole. There exist two constantly updated rankings of national teams: the FIFA/Coca-Cola World Ranking ${ }^{9}$ and the World Football Elo Ratings. ${ }^{10}$ Both rankings assign scores on the basis of historical data on games' results, strength of the opponents, goals scored, match importance, and game location, but they use different weighting schemes. Whereas a friendly game, for example, counts half as much as a World Cup final in the FIFA/Coca-Cola World Ranking, the World Football Elo Rating weights a World Cup final three times as much as a friendly game. The survey article of Stefani and Pollard (2007) carefully described and compared the two rating systems and concluded that the Elo system better predicts the quality of national teams. Given the focus of our article-major international soccer tournaments-we act on the advice of Stefani and Pollard and use the scores of the World Football Elo Ratings 1 month before the competition as a proxy for a national team's playing strength. ${ }^{11}$ We assume that the higher the combined Elo scores of the two teams in a match, the higher the (absolute) quality of the game expected by potential consumers. The competitive balance of a game is measured by the absolute value of the difference of scores in the World Football Elo Rating.

To test the influence of patriotism on TV ratings, we use data on the number of foreigners living in Switzerland in the year of the competition split by nationality. The Federal Office for Migration defines foreigners as individuals who permanently live in Switzerland and have not (yet) applied for Swiss citizenship. Bearing in mind that Swiss citizenship cannot be obtained unless the candidate has been a permanent resident for at least 5 years, is able to fluently speak one of the national languages, and shows integration into Swiss habits, customs, and traditions, it is likely that Swiss citizens adopt a positive attitude, including patriotic feelings, for Switzerland. We assume that for those immigrants who successfully applied for Swiss citizenship, searching costs economies to find other Swiss fans dominate over the path dependencies of former consumption patterns. ${ }^{12}$ Given the specificity of consumption capital

\footnotetext{
${ }^{9}$ See www.fifa.com/worldfootball/ranking.

${ }^{10}$ Advanced Satellite Consulting calculates the World Football Elo Ratings on a daily basis and publishes them on the Web page www.eloratings.net.

${ }^{11}$ Sensitivity analyses, however, have shown that the main results of our article would not change if the FIFA/CocaCola ranking was used instead of the Elo ranking. The correlation between the two ratings is 0.81 .

${ }^{12}$ This is, of course, a simplification. Sometimes the emotional attachment to the native country is barely weakened even for assimilated immigrants who became Swiss citizens long ago (e.g., second- or third-generation immigrants). The potential distortion, however, is negligible because the accumulated number of naturalizations between 1993 and 2005 is only one fifth of the total number of foreigners in 2006 (Bundesamt für Migration, 2005, 2007).
} 
and the often considerable language transaction costs, foreigners, however, are expected to stick to the national team representing their nation of origin even after having lived abroad for years. Thus, the higher the number of residents from a given country, the higher the expected TV ratings of the corresponding national team performances become.

To eliminate alternative explanations, we also control for several characteristics of the game. We conjecture that games scheduled on weekends will have comparatively higher TV ratings and games scheduled before 6 p.m. will have lower TV ratings due to different opportunity costs. ${ }^{13}$ Some of the last games of the group stage in a tournament are played simultaneously. Because sports consumers typically prefer watching "live" performances over video replays (Lucifora \& Simmons, 2003, p. 37), we included a dummy for all simultaneously played games that did not receive live TV coverage by any of the $17 \mathrm{TV}$ channels in our sample. ${ }^{14}$ The knockout games are assumed to be more exciting than games in the group phase. Thus, we use dummies for the last 16 (for the World Cups), the quarterfinals, the semifinals, and the final.

Because outliers can have an overwhelming influence on the regression results, especially with small data sets, the variables were checked for outliers. Not surprisingly, it was found that all games played by the Swiss national team (in total, 7 games) are outliers. As the Swiss population accounts for over $75 \%$ of the total population, it is definitively an extreme value. Therefore, we dropped the Swiss games, which would otherwise distort our results. In Table 1, the variables, as well as the descriptive statistics, are listed.

\section{RESULTS}

We estimated a pooled ordinary least square regression, resulting in a cases-to-variables ratio of 14. Although this is not as high as one would like, it is clearly above the threshold level in social sciences of 10 suggested by Tabachnick and Fidell (2001). ${ }^{15}$ Tournament-specific shifts are accounted for using competition dummies. Scatter plots of residuals were examined and indicated no violation of regression assumptions. Variance inflation factors are well below 10 for all regressors. Hence, we are not concerned with multicollinearity.

\footnotetext{
${ }^{13}$ Because our TV figures do not include persons who watch the games in restaurants or special public viewing areas, we also experimented with weather variables (dummy for rain and thunderstorm and the temperature) to proxy the likelihood of watching a game in public. However, these variables neither had any statistical significance nor changed the other coefficients. Infront Sports and Media Company estimated that at the FIFA World Cup 2006, 8\% of the TV audience watched the games in public (FIFA, 2007). An anonymous referee noted that if public viewing is more popular among immigrants, the impact of patriotism is likely to be underestimated.

${ }^{14}$ Of course, the broadcaster's allocation of the live TV coverage is not exogenous. It is rather likely that aspects of quality or patriotism influence this decision. However, a probit or logit estimation does not indicate a statistically significant impact of game quality and patriotism on the probability of receiving live TV coverage.

${ }^{15}$ To allow for varying impacts of game quality and patriotism on TV audiences across the different competitions, we additionally ran an ordinary least square regression for each tournament separately. Separate estimates generally support the findings of the pooled regression illustrated in Table 2, except for the European Championship 2000, for which neither game quality nor patriotism significantly affected the TV ratings. However, as the cases-to-variables ratios are less than 10, these results have to be interpreted very cautiously (Tabachnick \& Fidell, 2001).
} 
TABLE 1

Variables and Descriptive Statistics

\begin{tabular}{|c|c|c|c|c|c|c|c|c|c|}
\hline \multirow[b]{2}{*}{ Variable } & \multirow[b]{2}{*}{ Description } & \multicolumn{2}{|c|}{$\begin{array}{c}\text { European } \\
\text { Championship } \\
2000\end{array}$} & \multicolumn{2}{|c|}{$\begin{array}{l}\text { World Cup } \\
\quad 2002\end{array}$} & \multicolumn{2}{|c|}{$\begin{array}{l}\text { European } \\
\text { Championship } \\
2004\end{array}$} & \multicolumn{2}{|c|}{$\begin{array}{l}\text { World Cup } \\
\quad 2006\end{array}$} \\
\hline & & $M$ & $S D$ & $M$ & $S D$ & $M$ & $S D$ & $M$ & $S D$ \\
\hline \multicolumn{10}{|c|}{ (Absolute) game quality } \\
\hline Elo sum & $\begin{array}{l}\text { Sum of scores in the } \\
\text { World Football Elo } \\
\text { Rating }\end{array}$ & $3,676.9$ & 144.0 & $3,592.8$ & 131.0 & $3,578.7$ & 145.0 & $3,621.5$ & 169.0 \\
\hline \multicolumn{10}{|c|}{ Competitive balance } \\
\hline Elo difference & $\begin{array}{l}\text { Absolute value of the } \\
\text { difference of scores } \\
\text { in the World Football } \\
\text { Elo Rating }\end{array}$ & 110.7 & 97.8 & 115.6 & 85.2 & 148.5 & 112.2 & 147.2 & 114.7 \\
\hline \multicolumn{10}{|l|}{ Patriotism } \\
\hline Patriotism & $\begin{array}{l}\text { Sum of citizens of the } \\
\text { playing nations living } \\
\text { in Switzerland (in } \\
1,000 \text { ) }\end{array}$ & 160.1 & 120.1 & 66.4 & 81.2 & 109.5 & 97.4 & 104.4 & 116.1 \\
\hline \multicolumn{10}{|l|}{ Control variables } \\
\hline Weekend & $\begin{array}{l}\text { Games scheduled on } \\
\text { Saturday or Sunday } \\
\text { (dummy) }\end{array}$ & 0.43 & & 0.36 & & 0.35 & & 0.38 & \\
\hline Afternoon & $\begin{array}{l}\text { Games scheduled before } \\
6 \text { p.m. (dummy) }\end{array}$ & 0.00 & & 0.00 & & 0.00 & & 0.36 & \\
\hline Not-live & $\begin{array}{l}\text { Games without any live } \\
\text { TV coverage } \\
\text { (dummy) }\end{array}$ & 0.03 & & 0.09 & & 0.00 & & 0.09 & \\
\hline Last 16 & $\begin{array}{l}\text { Knockout games at the } \\
\text { last } 16 \text { (dummy) }\end{array}$ & 0.00 & & 0.14 & & 0.00 & & 0.14 & \\
\hline Quarter final & $\begin{array}{l}\text { Knockout games of the } \\
\text { last } 8 \text { (dummy) }\end{array}$ & 0.13 & & 0.07 & & 0.13 & & 0.07 & \\
\hline Semifinal & $\begin{array}{l}\text { Semifinals, including } \\
\text { the third-place } \\
\text { playoff (dummy) }\end{array}$ & 0.07 & & 0.05 & & 0.07 & & 0.05 & \\
\hline Final & Final & 0.03 & & 0.02 & & 0.03 & & 0.02 & \\
\hline $\begin{array}{l}\text { Number of obser } \\
\text { of the Swiss n }\end{array}$ & $\begin{array}{l}\text { tions (excluding games } \\
\text { ional team) }\end{array}$ & 31 & & 64 & & 28 & & 60 & \\
\hline
\end{tabular}

The estimates in Table 2 reveal that both game quality and patriotism are strong predictors of TV audience, whereas competitive balance seems to be irrelevant. Teams with high scores in the Elo ranking attract significantly more spectators than teams to which lower scores were assigned. In addition, the decision to watch a game seems to be largely driven by the national affiliation. The number of foreign residents living in Switzerland is strongly associated with the TV audiences of games in which the corresponding national teams are playing. The coefficients of the control variables have the expected signs and are highly significant (except the dummy for the European Championship tournament in 2004). Weekend games enjoy higher TV audiences than midweek games. The fact that a game is scheduled before $6 \mathrm{p} . \mathrm{m}$. or did not receive live TV coverage considerably decreases its TV ratings. The knockout games have significantly larger audiences than games in the group phase, with an increasing markup as the tournament approaches the final. 
TABLE 2

Pooled Regression Results: Estimates of TV Audience

\begin{tabular}{|c|c|c|}
\hline Variable & $\beta$ & $S E$ \\
\hline Elo sum & $692.0 * *$ & 126.2 \\
\hline Elo difference & 20.5 & 198.8 \\
\hline Patriotism & $722.4 * *$ & 189.7 \\
\hline Weekend & $124,599.2 * *$ & $38,331.1$ \\
\hline Afternoon & $-410,729.2 * *$ & $54,092.2$ \\
\hline Not live & $-248,173.4^{*}$ & 82.752 .3 \\
\hline Last 16 & $202,381.1 * *$ & $44,832.5$ \\
\hline Quarter final & $310,339.1 * *$ & $50,896.5$ \\
\hline Semifinal & $655,762.3 * *$ & $87,622.2$ \\
\hline Final & $1,294,724.0 * *$ & $57,007.9$ \\
\hline European Championship 2000 & $-328,623.3 * *$ & $60,476.5$ \\
\hline World Cup 2002 & $-132,661.2 * *$ & $37,122.7$ \\
\hline European Championship 2004 & $-6,509.7$ & $76,357.2$ \\
\hline Constant & $-1,769,970.0 * *$ & $461,958.1$ \\
\hline$R^{2}$ & 0.820 & \\
\hline Number of observations & 183 & \\
\hline
\end{tabular}

Note. Standard errors are White robust. Significance tests are one-tailed for directional variables and two-tailed for control variables.

$* P=.01 . * * P=.001$

\section{Robustness Analyses}

In this section, we examine the robustness of our results in a twofold manner: First, we analyze three sub-samples with varying foreigner compositions; second, we allow for the possibility that people might have supportive attitudes toward more than just one country. Switzerland has four official languages: German $(64 \%)$ in the north and center; French $(20.4 \%)$ in the west; Italian $(6.5 \%)$ in the south; and Romansh $(0.5 \%)$, which is spoken locally by a small minority, in the southeastern region. This peculiarity of Switzerland as a multilingual and multicultural country helps us to investigate the influence of patriotism on the TV ratings in more detail. We are fortunate to have both the TV ratings and the data of the different immigrant groups for each of the three main language areas of Switzerland.

The density of particular groups of foreigners in a certain region is highly affected by the spoken language. The illustrations in the left column of Figure 1 display that French immigrants are most likely to settle down in the French-speaking part of Switzerland, the Italians in the Italian-speaking region, and the German immigrants in the German-speaking area (relative to the total number of people living in that area). For a first visual test, we compare the relative average TV audiences of games featuring the German, French, and Italian national teams, respectively, with the population shares of German, French, and Italian foreigners in the three different language areas.

The illustrations in Figure 1 show that the different shares of Germans, French, and Italians in the different language areas are well-reflected in the relative TV audiences of the corresponding national team performances in all four tournaments. The Italian national team enjoys the highest 

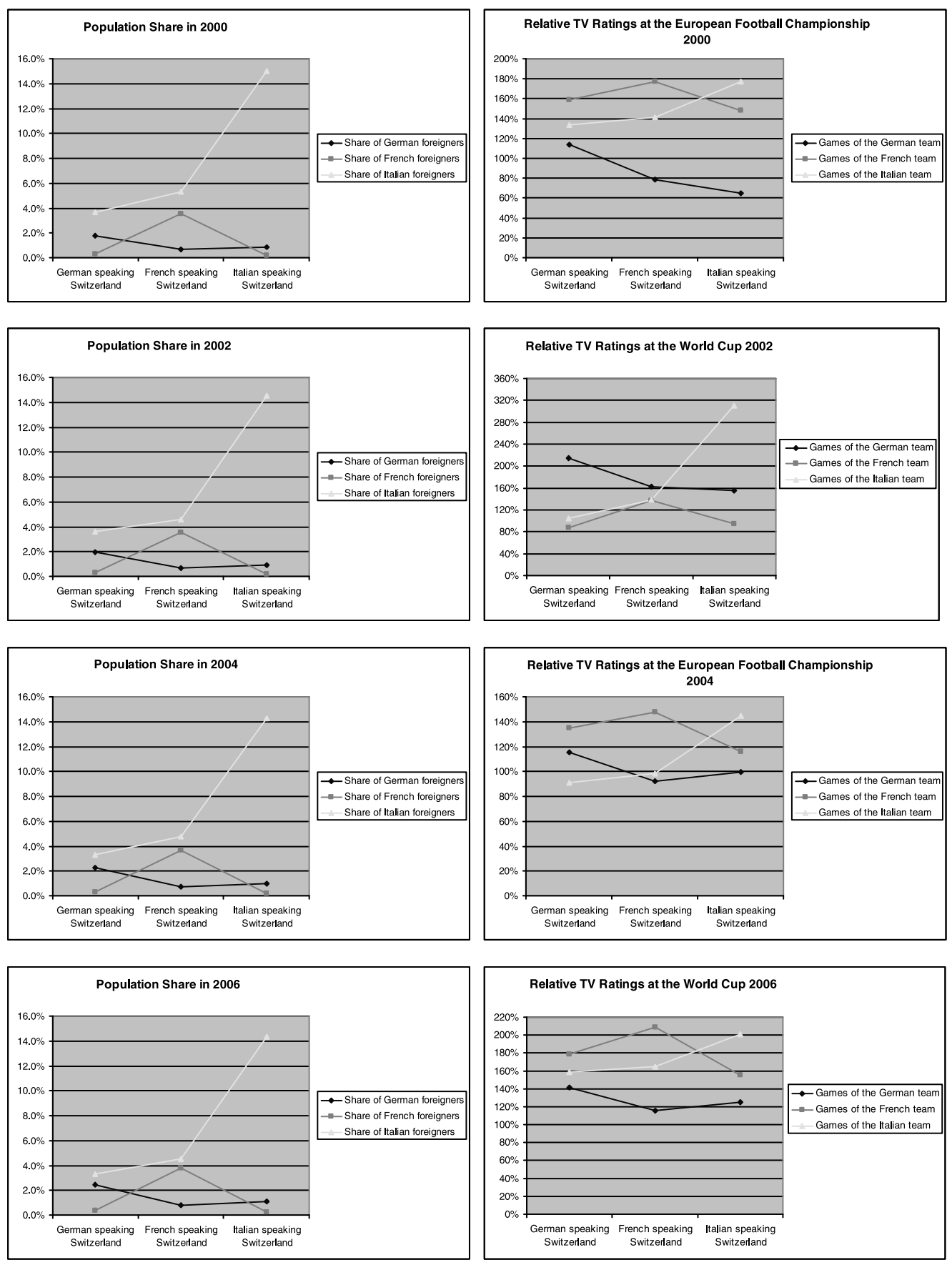

FIGURE 1 Shares of German, Italian, and French immigrants in the three language areas of Switzerland and relative TV audience per game of the corresponding national team performances. 
TV audience share in the Italian-speaking region, the French team in the French-speaking area, and the German national team in the German-speaking part of Switzerland. Of course, this does not yet prove that patriotism alone drives this result. We have to especially address the possibility that the demand of the "big three" European national teams might be driven by reduced language transaction costs in the corresponding regions (see the subsequent section in this article). However, the apparent relation between the population shares and the relative TV ratings does not disappear if we control for game quality, competitive balance, and other game-specific characteristics. Table 3 displays separate estimates regarding the three language areas. The influence of patriotism thereby shows high robustness.

So far, we have treated patriotism as a positive and supportive attitude toward just one country (according to political citizenship). However, regarding Switzerland (and other multicultural and multiethnic countries), it is possible that the extent of identification with and pride in the nation might vary considerably, even among people having the same political nationality. Instead of supporting just one national team and being indifferent to all others, people could have multiple favored teams.

Both the languages and the cultures of Switzerland are highly influenced by its neighbors, especially the French- and the Italian-speaking minorities. People living in the French-speaking area tend to be geared slightly more to the French culture, and the Italian-speaking region is affected by Italy, both in lingual and cultural facets. The Swiss have even created a special word, Röstigraben, to describe the dividing line between the different mentalities and the latent conflict between the German-speaking majority and the French-speaking minority.

In the following, we investigate the eventuality that individuals (mainly the Swiss) living in the minority language areas of Switzerland might have a special affection for the neighboring national teams, regardless of their political citizenship. Apart from their first-order attachment

TABLE 3

Estimates of TV Audience Split Into the Three Language Areas of Switzerland

\begin{tabular}{|c|c|c|c|c|c|c|}
\hline \multirow[b]{2}{*}{ Variable } & \multicolumn{2}{|c|}{$\begin{array}{l}\text { German-Speaking } \\
\text { Switzerland }\end{array}$} & \multicolumn{2}{|c|}{$\begin{array}{l}\text { French-Speaking } \\
\text { Switzerland }\end{array}$} & \multicolumn{2}{|c|}{$\begin{array}{l}\text { Italian-Speaking } \\
\text { Switzerland }\end{array}$} \\
\hline & $\beta$ & $S E$ & $\beta$ & $S E$ & $\beta$ & $S E$ \\
\hline Elo sum & $502.1 * * *$ & 93.6 & $149.8 * * *$ & 32.0 & $31.2 * * *$ & 5.1 \\
\hline Elo difference & -2.1 & 147.0 & 4.9 & 50.1 & 10.1 & 8.7 \\
\hline Patriotism & $676.4 * *$ & 211.1 & $890.3^{* * *}$ & 178.0 & $658.4^{* * *}$ & 57.7 \\
\hline Weekend & $111,084.3^{* * *}$ & $27,763.1$ & $9,468.7$ & $10,488.1$ & $3,740.1^{*}$ & $1,625.5$ \\
\hline Afternoon & $-303,056.2 * * *$ & $40,019.2$ & $-95,665.2 * * *$ & $14,007.0$ & $-11,254.7 * * *$ & $2,532.4$ \\
\hline Not live & $-168.124 .1^{*}$ & $65,096.0$ & $-71,933.7^{* * *}$ & $15,616.0$ & $-8,333.3^{* *}$ & $3,072.5$ \\
\hline Last 16 & $139,121.8 * * *$ & $31,717.4$ & $55,399.8^{* * *}$ & $13,119.1$ & $8,054.3 * *$ & $2,500.3$ \\
\hline Quarter final & $227,039.6 * * *$ & $37,791.3$ & $71,761.0^{* * *}$ & $12,548.0$ & $10,828.9 * * *$ & $2,528.2$ \\
\hline Semifinal & $496,766.6 * * *$ & $64,205.7$ & $135,504.1 * * *$ & $24,545.4$ & $21,685.3 * * *$ & $3,051.8$ \\
\hline Final & $965,946.4 * * *$ & $44,514.5$ & $283,608.7^{* * *}$ & $17,283.3$ & $43,005.8^{* * *}$ & $5,052.2$ \\
\hline European Championship 2000 & $-234,167.5^{* * *}$ & $45,662.6$ & $-78,800.4^{* * *}$ & $14,741.4$ & $-15,700.5^{* * *}$ & $2,527.7$ \\
\hline World Cup 2002 & $-113,467.2 * * *$ & $27,687.2$ & $-12,259.1$ & $9,859.9$ & $-7,037.7^{* * *}$ & $2,078.0$ \\
\hline European Championship 2004 & $-2,476.4$ & $57,185.9$ & $-3,001.2$ & $19,039.2$ & $-1,347.1$ & $2,820.2$ \\
\hline Constant & $-1,280,510.0 * * *$ & $344,876.6$ & $-374,333.2 * * *$ & $116,470.6$ & $-82,723.7^{* * *}$ & $18,665.4$ \\
\hline$R^{2}$ & \multicolumn{2}{|l|}{0.814} & \multicolumn{2}{|l|}{0.797} & \multicolumn{2}{|l|}{0.815} \\
\hline Number of observations & \multicolumn{2}{|l|}{183} & \multicolumn{2}{|l|}{183} & \multicolumn{2}{|l|}{183} \\
\hline
\end{tabular}

Note. Standard errors are White robust. Significance tests are one-tailed for directional variables and two-tailed for control variables. $* P=.05$. $* * P=.01$. $* * * P=.001$ 
TABLE 4

Estimates of TV Audience Considering Lingual and Cultural Similarity

\begin{tabular}{|c|c|c|c|c|}
\hline \multirow[b]{2}{*}{ Variable } & \multicolumn{2}{|c|}{$\begin{array}{l}\text { French-Speaking } \\
\text { Switzerland }\end{array}$} & \multicolumn{2}{|c|}{$\begin{array}{c}\text { Italian-Speaking } \\
\text { Switzerland }\end{array}$} \\
\hline & $\beta$ & $S E$ & $\beta$ & $S E$ \\
\hline Elo sum & $128.6^{*}$ & 36.0 & $31.2 * *$ & 6.0 \\
\hline Elo difference & -15.2 & 50.0 & 2.5 & 8.5 \\
\hline Patriotism & $748.2 * *$ & 212.0 & $603.4 *$ & 427.1 \\
\hline French team & $37,237.7$ & $22,402.6$ & -769.1 & $3,293.2$ \\
\hline Italian team & $13,875.4$ & $13,955.1$ & $2,344.1$ & $18,994.4$ \\
\hline$R^{2}$ & \multicolumn{2}{|c|}{0.803} & \multicolumn{2}{|c|}{0.813} \\
\hline Number of observations & \multicolumn{2}{|c|}{183} & \multicolumn{2}{|c|}{183} \\
\hline
\end{tabular}

Note. Standard errors are White robust. Significance tests are one-tailed for directional variables and two-tailed for control variables. The model also includes dummies for afternoon games, weekend games, games without live TV coverage, the last 16, the quarter finals, the semifinals, the final, as well as three different competition dummies (the World Cup 2006 is the reference category).

$$
* P=.10 . * * P=.001 \text {. }
$$

to the Swiss nation, the Italian- and French-speaking Swiss minorities could possibly feel emotional about the Italian or French national team, respectively, due to their shared lingual and similar cultural background. Hence, we include a dummy that identifies all games of the French national team and the Italian team.

As Table 4 shows, people living in the French- or Italian-speaking regions exhibit no special interest in the French or Italian national teams. It seems that the second-order lingual or cultural similarities do not additionally help to explain the TV audience figures of national team games. Even in a multilingual and multicultural country like Switzerland, it is rather the first-order attachment according to political citizenship that defines whether someone is going to watch a national team competition. ${ }^{16}$

\section{CONCLUSION}

This study investigates the determinants of a TV audience at four major international soccer competitions: the UEFA European Football Championships in 2000 and 2004 and the FIFA World Cups in 2002 and 2006. The results indicate that the demand for televised national team games is largely driven by the expected game quality based on the proven playing strength of the opponents, as well as by patriotism. The number of residents coming from a given country living in Switzerland is a good predictor of the Swiss TV ratings for the corresponding national team games. The relation between soccer and patriotism seems to be very powerful. An exogenous shock of, for example, 1,000 additional Portuguese immigrants living in Switzerland is likely to enhance the TV ratings of the games of the Portuguese national team by around 700 .

\footnotetext{
${ }^{16}$ The significance level of the patriotism effect in the Italian-speaking region (right column in Table 4) decreased to the .10 level as the patriotism variable correlates highly with the dummy Italian team.
} 
Of course, strictly speaking, we only find a correlation between particular population groups and TV figures, without being able to detect the exact causality chain. Additional psychological and sociological studies are required to explore the relation between patriotism and fan support in greater depth. Nevertheless, we consider patriotism as the most plausible explanation for the robust relation between TV audience and the size of the corresponding nationalities.

We know from demand studies in club soccer that gate attendance is positively related to a team's market - typically approximated by the metropolitan statistical area (e.g., Borland \& MacDonald, 2003; Schmidt \& Berri, 2001; Simmons, Buraimo, \& Forrest, 2007). Our results indicate that regarding the TV audiences of national team competitions, the relevant market is not geographically but nationally segmented. Patriotism plays a crucial role in shaping viewing habits. Immigrants tend to stick to their native country even when living abroad. From an economic standpoint, the strong national differences in consumer behavior may be explained by historical path dependencies of a habit-forming activity, which creates lock-in effects and significant switching costs. From a socio-psychological perspective, the national team seems to be an important object of social identification that facilitates the crucial feelings of belongingness and self-esteem.

\section{ACKNOWLEDGMENTS}

We are grateful to Benjamin Compaine, David Forrest, Bruno S. Frey, Steve Lacy, Steve Wildman, two anonymous referees, the participants at the 11th Annual Conference of Sports Economics in Magglingen 2007, and the seminar participants at the University of Zurich for helpful comments. Remaining errors are, of course, our own.

\section{REFERENCES}

Adler, M. (1985). Stardom and talent. The American Economic Review, 75, 208-212.

Alavy, K., Gaskell, A., Leach, S., \& Szymanski, S. (2006). On the edge of your seat: Demand for football on television and the uncertainty of outcome hypothesis (Working Paper No. 06-31). Retrieved September 4, 2008, from http://ideas.repec.org/s/spe/wpaper.html

Anderson, B. (1983). Imagined communities. London: Verso.

Ashforth, B. E., \& Mael, F. (1989). Social identity theory and the organization. Academy of Management Review, 14, 20-39.

Bogdanov, D. (2005). Measuring nationalism as a sportfan motive. Retrieved March 22, 2007, from http://etd.lib.fsu.edu/ theses/available/etd-11042005-171313/

Borland, J., \& MacDonald, R. (2003). Demand for sport. Oxford Review of Economic Policy, 19, 478-502.

Bundesamt für Migration. (2005). Ausländer- und Asylstatistik [Statistics of foreign population and asylum]. Bern: Schweizerische Eidgenossenschaft.

Bundesamt für Migration. (2007). Ausländerstatistik [Statistics of foreign population]. Bern: Schweizerische Eidgenossenschaft. Retrieved March 30, 2007, from www.bfm.admin.ch

Cho Han, H. (2004). Beyond the FIFA's World Cup: An ethnography of the local in South Korea around the 2002 World Cup. Inter-Asia Cultural Studies, 5, 8-26.

Fédération Internationale de Football Association. (2007). The FIFA World Cup broadcast wider, longer and farther than ever before. Retrieved April 16, 2007, from www.fifa.com

Forrest, D., Simmons, R., \& Buraimo, B. (2005). Outcome uncertainty and the couch potato audience. Scottish Journal of Political Economy, 52, 641-661. 
Franck, E., \& Nüesch, S. (2008). Alles nur patrioten?-Eine empirische analyse der fernsehnachfrage während der FIFA WM 2006 [Just patriots?-An empirical analysis of the TV demand during the FIFA World Cup 2006]. In H. Dietl, E. Franck, \& H. Kempf (Eds.). Fußball-Die ökonomie einer leidenschaft (pp. 79-99). Magglingen, Switzerland: Hofmann.

Hammervold, R., \& Solberg, H. A. (2006). TV sports programs-Who is willing to pay to watch? Journal of Media Economics, 19, 147-162.

Kuypers, T. (1996). The beautiful game? An econometric study of why people watch English football (Discussion Paper in Economics 96-01). London: University College of London.

Lang, K. (1986). A language theory of discrimination. The Quarterly Journal of Economics, 101, 363-382.

Lazear, E. (1999). Culture and language. Journal of Political Economy, 107, 95-125.

Lucifora, C., \& Simmons, R. (2003). Superstar effects in sport. Evidence from Italian soccer. Journal of Sports Economics, 4, 35-55.

Madrigal, R. (1995). Cognitive and affective determinants of fan satisfaction with sporting event attendance. Journal of Leisure Research, 27, 205-227.

Markovits, A. S., \& Hellerman, S. L. (2001). Offside. Soccer \& American exceptionalism. Princeton, NJ: Princeton University Press.

Marshall, A. (1923). Principles of economics (8th ed.). London

Mummendey, A., Klink, A., \& Brown, R. (2001). Nationalism and patriotism: National identification and out-group rejection. British Journal of Social Psychology, 40, 159-172.

Neale, W. C. (1964). The peculiar economics of professional sports: A contribution to the theory of the firm in sporting competition and in market competition. The Quarterly Journal of Economics, 78, 1-14.

Pollak, R. A. (1970). Habit formation and dynamic demand functions. Journal of Political Economy, 78, 745-763.

Rottenberg, S. (1956). The baseball players' labor market. Journal of Political Economy, 64, 242-258.

Rottenberg, S. (2000). Resource allocation and income distribution in professional team sports. Journal of Sports Economics, 1, 11-20.

Schmidt, M. B., \& Berri, D. J. (2001). Competitive balance and attendance. The case of Major League Baseball. Journal of Sports Economics, 2, 145-167.

Simmons, R., Buraimo, B., \& Forrest, D. (2007). Freedom of entry, market size and competitive outcome: Evidence from English soccer. Southern Economic Journal, 74, 204-213.

Spinnewyn, F. (1981). Rational habit formation. European Economic Review, 15, 91-109.

Stefani, R., \& Pollard, R. (2007). Football rating systems for top-level competition: A critical survey. Journal of Quantitative Analysis in Sports, 3, 1-19.

Stigler, G., \& Becker, G. (1977). De gustibus non est disputandum. The American Economic Review, 67, 76-90.

Szymanski, S. (2003a). The assessment: The economics of sport. Oxford Review of Economic Policy, 19, 467-477.

Szymanski, S. (2003b). The economic design of sporting contests. Journal of Economic Literature, 16, 1137-1187.

Tabachnick, B. G., \& Fidell, L. S. (2001). Using multivariate statistics. Boston: Allyn \& Bacon.

Tajfel, H., \& Turner, J. C. (1985). The social identity theory of intergroup behavior. In S. Worchel \& A. G. Austin (Eds.), Psychology in intergroup relations (pp. 7-24). Chicago: Nelson-Hall. 